\title{
Effectiveness of Laser Acupoints on Women With Polycystic Ovarian Syndrome: A Randomized Controlled Trial
}

\author{
Fayiz F. El-Shamy ${ }^{1 *}$, Sand S. El-kholy ${ }^{2}$, Marwa M. Abd El-Rahman ${ }^{3}$ \\ 'Department of Physical Therapy for Women's Health, Faculty of Physical Therapy, Kafrelsheikh University, Kafrelsheikh, \\ Egypt \\ ${ }^{2}$ Department of Physiology, Faculty of Medicine, Kafrelsheikh University, Kafrelsheikh, Egypt \\ ${ }^{3}$ Department of Physical Therapy for Gynaecology and Obstetrics, Faculty of Physical Therapy, Cairo University, Cairo, Egypt
}

\author{
*Correspondence to \\ Fayiz F. El-Shamy; Department \\ of Physical Therapy for Women's \\ Health, Faculty of Physical Therapy, \\ Kafrelsheikh University, Kafrelsheikh, \\ Egypt. \\ Tel: 002/01091050154; \\ Email: ff_elshamy@yahoo.com
}

Published online 20 March 2018

\begin{abstract}
Introduction: Polycystic ovarian syndrome (PCOS) is one of the most widely recognized reasons for infertility. The aim of this study was to examine the impact of laser acupuncture on PCOS women.

Methods: Twenty-five PCOS women were randomly allocated to either the study group (SG; $\mathrm{n}=13$ ), treated by laser acupuncture, or the control group (CG; $n=12$ ). Blood hormonal levels and insulin resistance were measured at baseline and after 12 weeks of intervention.

Results: The pre-intervention levels showed no statistically significant differences between SG and CG for baseline characteristics $(P>0.05)$. After 12 weeks of intervention, within-group analyses showed that body mass index $(\mathrm{BMI})$, blood hormonal levels, and insulin resistance were significantly decreased $(P<0.05)$, while no significant changes in follicle-stimulating hormone $(P>0.05)$ were recorded in the 2 groups. Between-groups analyses showed that most outcomes measures were significantly decreased $(P<0.05)$ in SG compared with $\mathrm{CG}$, with no significant changes in FSH and BMI $(P>0.05)$.

Conclusion: Laser acupuncture can be suggested as an effective management for PCOS women. Keywords: Polycystic ovary syndrome; Blood hormonal levels; Insulin resistance; Laser; Acupuncture.
\end{abstract}

\section{Introduction}

Polycystic ovarian syndrome (PCOS), is the most recognized endocrine dysfunction affecting 5 to $10 \%$ women of reproductive age. ${ }^{1}$ While about $21 \%$ of women have PCOS, ${ }^{2}$ it impacts $15 \%-20 \%$ of infertile women. ${ }^{3}$ Insulin resistance (IR) is the most well-known characteristics of PCOS, represented in $85 \%$ of these women. ${ }^{4}$ An additional basic aspect of PCOS, high androgen levels, influences about $60 \%$ to $80 \%$ of PCOS women and is able to produce medical signs such as hirsutism, acne, and alopecia. ${ }^{5}$

The National Institutes of Health (NIH) suggested investigative criteria for PCOS requiring the concurrent existence of androgen excess (biochemical and/or clinical) and ovarian disorder. ${ }^{6}$ In 2003, the Rotterdam criteria define PCOS as the presence of at least 2 criteria from androgen excess, ovulatory disorder and polycystic ovarian morphology. ${ }^{7}$ The Androgen Excess Society (AES) reviewed PCOS investigative criteria that need to exits as androgen excess and menstrual disorder and/or

\section{PCO morphology. ${ }^{8}$}

However, the actual incidence of PCOS in the society is the theme of a persisting discussion due to the specific sampling methodology used in each of the different studies plus study design limitations. Nevertheless, PCOS incidence based on the NIH criteria is appraised to be about $6 \%$ to $8 \%,{ }^{9}$ with the application of the Rotterdam criteria, the incidence increased to $15 \%$ to $25 \%,{ }^{10}$ while the implementation of the Androgen, AES recommendations puts PCOS incidence at about 10 to $15 \%$. $^{9}$

PCOS is a complex of symptoms of unknown cause and is defined as a heterogeneous dysfunction that results in Hyperandrogenism, existing evidence suggests that the ovarian theca cells are the real wellspring of the androgen generation and emission which assume a key part in the PCOS etiology. ${ }^{11}$

In addition, the hypothalamic-pituitary-ovarian (HPO) axis and IR may cause the PCOS. Changes in the sympathetic nervous system activity have also been proposed in the list of causes of this syndrome. ${ }^{12}$ 
PCOS is related to the progress of severe endocrine, metabolic, cardiovascular, reproductive, and psychological problems. $^{2}$

Due to its heterogeneous nature, an effective treatment of PCOS requires a consistent, multi-axes strategy with interdisciplinary experience, established on a strong evidence base to guide the unification of care. Many women with PCOS require long-lasting treatment that extends from lifestyle interference to precise medical or surgical methods. Medical treatments are effective although have several complications. Oral contraceptives are used as the first-line of treatment in PCOS, they minimize hirsutism and acne but have many negative effects on glucose tolerance, coagulability and fertility. ${ }^{13}$

Acupuncture, a treatment that goes back 3000-5000 years of clinical practice, is a basic part of traditional Chinese medication and has turned out to be perceived in Western medicine more as a supplement or other choice to traditional treatments. Acupuncture therapy in female with PCOS and ovulatory disorder has been known to bring enduring useful results on the endocrine system and menstrual cycle, without complications. ${ }^{14}$

Laser acupuncture is considered to be an effective alternative to conventional needle acupuncture, is valuable in patients who are needle fearful, or can be used as a safe (e.g., virus $\mathrm{C}$ infection), non-invasive technique of treatment and a suitable method for stimulation of difficult points in the region of perineum or genitals. ${ }^{15} \mathrm{To}$ our knowledge, no trial study has been done to address the therapeutic effect of laser acupoints on women with reproductive disorders. For that reason, the purpose of the present study is to assess the outcome of laser acupoints on female with PCOS.

\section{Methods}

Participants

Twenty-nine female with PCOS $(n=29)$ aged between 19 and 23 years were recruited to the study in the gynecology department of the Kafrelsheikh General Hospital, Kafrelsheikh, Egypt. The evaluation procedures were explained to each participant. Prior to baseline measurements, 4 women dropped out, 2 because they wished to withdraw from the study and 2 were relocating to another city. Of the remaining women, 25 were haphazardly recruited for blood examinations.

Assessments were done at (1) baseline and (2) after 12 weeks of intervention, from April to December 2016.

\section{Inclusion and Exclusion Criteria}

The inclusion criteria were participants aged between 19 and 23 years, body mass index (BMI) not exceeding 30 $\mathrm{kg} / \mathrm{m}^{2}$. PCOS women were assignable for randomization if they had clinical and/or biochemical signs of androgen excess (hirsutism or acne), together with one of the next symptoms: oligomenorrhea or amenorrhea (oligomenorrhea is generally defined as a cycle duration of more than 35 days while in amenorrhea the inter-cycle period exceeds 90 days), screened polycystic ovaries $(\geq 12$ follicles with a $2-9 \mathrm{~mm}$ diameter on the ovary and/or ovarian volume $>10 \mathrm{~cm}^{3}$ ) disclosed by ultrasonography in one or both ovaries, according to the AES. ${ }^{8}$

Exclusion criteria were: recognized endocrine causes of hyperandrogenemia, androgen-secreting neoplasm, Cushing syndrome, acromegaly, hyperprolactinemia, thyroid dysfunction, hypothalamic amenorrhea, ovarian insufficiency, congenital adrenal or ovarian hyperplasia and a drug-related condition.

Each woman was excluded from the study if she missed 3 sessions.

\section{Design}

This is a randomized controlled trial with blinding of participants and examiners. As participants were blinded to the knowledge of the group they would create, since the participant selected a numbered envelope, which did not let the participant to know the group that she would comprise (study or control). Thus, the PCOS participants were randomized into blocks and allocated, using a simple, non-probability sampling method, to either the study group (SG; $n=13$ ), treated by laser acupoints or the control group ( $\mathrm{CG} ; \mathrm{n}=12$ ), which were treated by placebo laser acupoints.

\section{Sample-Size Calculation}

Assuming a 30\% improvement in blood hormonal levels of PCOS women in the study group, based on a sample with the power size estimation of the study beta of $80 \%$, and to detect the effect size of difference $5 \%$, with a significance level of $P<0.05,10$ participants were required.

\section{Intervention}

The condition of PCOS women randomized to the group treated by laser acupoints for 3 months was assessed at baseline and after 12 weeks (end of intervention), during which time they undertook two sessions per week during first 2 weeks, one session/week through 4 weeks, and one session every seconds week for 6 weeks, in a total of 11 sessions through 12 weeks. ${ }^{16}$

Acupoints selection was based on previous studies ${ }^{14}$ and clinical trials treating PCOS women.

Laser acupoints were selected according to innervations of the ovaries $\left(\mathrm{Th}_{12}-\mathrm{L}_{2}, \mathrm{~S}_{2}-\mathrm{S}_{4}\right)$ to modulate HPO and the hypothalamic-pituitary-adrenal (HPA) axes to support hormonal balance ${ }^{17}$ (Table 1).

An infrared laser (Acu-Lase, Petrolaser, Russia) with 830 $\mathrm{nm}$ wavelength, $10 \mathrm{~mW}$ power output and $0.5 \mathrm{~J}$ energy was applied 60 seconds for each acupoint. The head of the machine was used perpendicularly, with direct contact to each point.

The physiotherapist responsible for performing laser acupoints had experience in acupuncture within women's health. All participants in the intervention group were 
Table 1. Laser Acupoints With Anatomical Position and Innervation

\begin{tabular}{lll}
\hline Point & Location & Innervation \\
\hline Ren4 (Unilateral) & On the midline, 3 cun lower to the umbilicus. & Anterior cutaneous nerve of the subcostal nerve \\
Ren5 (Unilateral & On the midline, 2 cun lower to the umbilicus. & Anterior cutaneous branch of the $11^{\text {th }}$ intercostal nerve \\
St29 (Bilateral) & 4 cun under the umbilicus, 2 cun sideways to the midline. & The iliohypogastric nerve $($ Th \\
$6-12$ & ). \\
Sp6 (Bilateral) & $\begin{array}{l}3 \text { cun higher than the tip of the medial malleolus on the } \\
\text { posterior margin of the tibia. }\end{array}$ & $\begin{array}{l}\text { Superficially, the medial crural cutaneous nerve; deeper, } \\
\text { in the posterior aspect, the tibial nerve }\left(\mathrm{L}_{4-5} \mathrm{~S}_{1-2}\right) .\end{array}$ \\
\hline
\end{tabular}

Cun is the estimation of one "body inch" utilized to find acupuncture points. Estimation is constantly taken from the patient's hand. The breadth of the thumb is 1 cun, breadth of 2 fingers is 1.5 cun, 4 fingers are 3 cun.

given an info brochure, that included advice on a healthy diet as a low-carbohydrate and high-protein diet, ${ }^{18}$ high dietary fiber, and less saturated fat, ${ }^{19}$ were instructed to engage in aerobic exercise, fast walking for at least 30 - 45 min, 3 days a week. ${ }^{16}$ Women in the control group were treated by placebo laser acupoints with the same pieces of advice on healthy diet and exercise as in the intervention group.

Neither group was undergoing physiotherapy or any other treatment during the intervention period.

\section{Outcome Measures}

The whole analyses were performed at a certified laboratory at the Department of Clinical Chemistry, Kafrelsheikh General Hospital. Blood tests included serum free testosterone (FT), serum total testosterone (TT), luteinizing hormone (LH) and follicle-stimulating hormone (FSH), LH/FSH ratio, anti-Müllerian hormone $(\mathrm{AMH})$ and insulin sensitivity was calculated with a homeostasis model assessment of insulin resistance (HOMA-IR). ${ }^{20}$ Blood samples were taken independently on day 2 or 3 of the follicular phase of the menstrual cycle because the majority of the participants had ovarian dysfunction.

All the biochemical checkups were done for both groups (SG and CG) at (1) baseline and (2) after 12 weeks of intervention.

\section{Data Analysis}

The collected data were categorized, tabulated and analyzed using descriptive statistics in terms of mean \pm standard deviation, frequency, and percentage. The paired $t$ test was used to analyze and compare blood hormonal levels within each group (SG or CG) before and after the intervention. The independent $t$ test was carried out to evaluate differences between both groups (SG and CG) before and after the intervention. A $P$ value $<0.05$ was considered statistically significant. Data analysis was done using SPSS software version 16.

\section{Results}

Out of the 34 women originally contacted at their first visit, 29 achieved the inclusion criteria. Of these, 4 withdrew from the study and 25 PCOS women (aged 20 \pm 1.2 years) were randomly allocated into the study group (SG; $\mathrm{n}=13$ ) or a control group (CG; $\mathrm{n}=12$ ) (Figure 1 ).
PCOS phenotype according to $\mathrm{AES}^{8}$ was as follows: in the study group, $6(46.1 \%)$ had androgen excess and ovulatory dysfunction, $4(30.8 \%)$ had androgen excess and PCO morphology, and 3 (23.1\%) had androgen excess, ovulatory dysfunction, and PCO morphology; in the control group, $5(41.7 \%)$ had androgen excess and ovulatory dysfunction, 5 (41.7\%) had androgen excess and PCO morphology, and 2 (16.6\%) had androgen excess, ovulatory dysfunction, and PCO morphology.

Baseline characteristics of the participants are summarized in Table 2. There were no statistically significant differences between both groups (SG and CG) in any of these characteristics $(P>0.05)$.

The mean application of laser acupoints sessions in the study group was $10 \pm 0.1$ out of 11 possible sessions. Ten out of the 13 women in the study group (76.9\%) performed at least $9(81.8 \%)$ of weekly sessions. No hazards were reported by the participants.

Within-group analyses revealed that BMI, blood hormonal levels, and IR were significantly decreased $(P<0.05)$, with no significant change in FSH $(P>0.05)$ in the 2 groups (Tables 3 and 4 ) (Figures 2 and 3 ).

Between-group analyses at the end of intervention revealed that most outcomes measures were significantly decreased $(P<0.05)$ in SG contrasted with $C G$, with no significant changes in FSH and BMI $(P>0.05)$ between the two groups (Table 5) (Figure 4).

Menstrual and ovulation frequencies were as follows: in the study group, 9 of 13 (69.23\%) were oligo-or amenorrhoeic before the intervention and $6(66.7 \%)$ reported 3 regular menses throughout the study: in the control group, 7 of $12(58.33 \%)$ were oligo-or amenorrhoeic before the intervention and $5(41.67 \%)$ reported 3 regular menses throughout the study.

\section{Discussion}

The purpose of our study was to investigate the impact of treatment with laser acupoints on PCOS women. The progress in the different outcomes was evaluated by comparing the post-treatment results with those at the pretreatment, evaluating improvement within group separately. In addition, we compared the results between both groups.

This study showed that, within groups, we have found an enhancement in all measures at the end of the intervention, with no significant variation within the two 


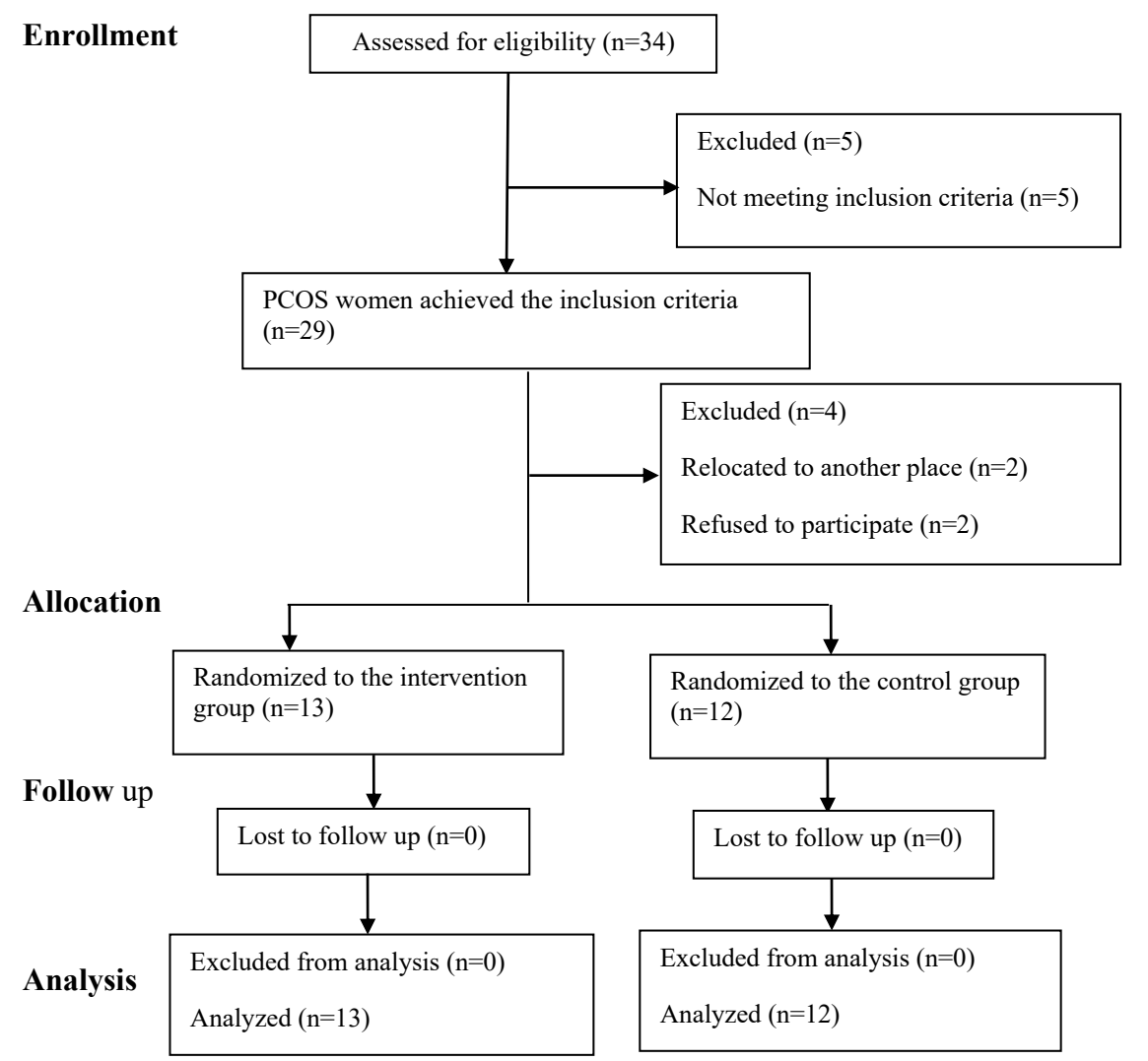

Figure 1. Flowchart of the Participants During the Study.

groups regarding the FSH level.

PCOS women demonstrate a state of IR and hyperinsulinemia, thus, androgen generation can be overstimulated. This is mainly obvious in the existence of increased BMI. ${ }^{21}$ Hyperinsulinemia contributes to the unusual gonadotropin-releasing hormone $(\mathrm{GnRH})$ secretion, in spite of the fact that the mechanism is not clear. $^{22}$

An increase in serum LH levels is conflictingly found in

Table 2. Baseline Characteristics of PCOS Women in the 2 groups

\begin{tabular}{lccc}
\hline & \multicolumn{2}{c}{$\begin{array}{c}\text { Mean } \pm \text { SD of Baseline Characteristics of } \\
\text { Participants }\end{array}$} & P Value \\
\cline { 2 - 3 } Variables & $\begin{array}{c}\text { Study Group } \\
(\mathbf{n}=\mathbf{1 1})\end{array}$ & $\begin{array}{c}\text { Control Group } \\
(\mathbf{n}=\mathbf{1 0})\end{array}$ & \\
\hline Age $(\mathrm{y})$ & $20.2 \pm 0.3$ & $19.8 \pm 0.8$ & 0.52 \\
$\mathrm{BMI}\left(\mathrm{kg} / \mathrm{m}^{2}\right)$ & $27.15 \pm 2.1$ & $26.9 \pm 1.7$ & 0.61 \\
$\mathrm{FT}, \mathrm{ng} / \mathrm{dL}$ & $2.1 \pm 0.1$ & $1.9 \pm 0.3$ & 0.19 \\
$\mathrm{TT}, \mathrm{ng} / \mathrm{dL}$ & $69.5 \pm 2.1$ & $66.3 \pm 1.3$ & 0.20 \\
$\mathrm{LH}, \mathrm{mIU} / \mathrm{mL}$ & $10.1 \pm 1.3$ & $11.3 \pm 0.3$ & 0.63 \\
$\mathrm{FSH}, \mathrm{mIU} / \mathrm{mL}$ & $4.9 \pm 0.8$ & $5.0 \pm 0.2$ & 0.70 \\
$\mathrm{LH} / \mathrm{FSH}$ ratio & $2.4 \pm 0.3$ & $2.5 \pm 0.5$ & 0.81 \\
$\mathrm{AMH}, \mathrm{ng} / \mathrm{mL}$ & $12.0 \pm 1.9$ & $13.3 \pm 1.4$ & 0.31 \\
$\mathrm{HOMA}-\mathrm{IR}$ & $2.9 \pm 1.3$ & $2.5 \pm 1.4$ & 0.21 \\
\hline
\end{tabular}

HOMA-IR, the indicator of which was considered according to the rule: [fasting plasma glucose $(\mathrm{mg} / \mathrm{dL}) \times$ fasting plasma insulin concentration $(\mathrm{mU} / \mathrm{L})] / 405$.
PCOS women, due to a GnRH increase in the sufficiency and recurrence of pulsatile LH secretory pattern. ${ }^{23}$ Levels of FSH in PCOS appear to be within the lower follicular range, and response to $\mathrm{GnRH}$ is relatively similar to ovulatory controls. ${ }^{24}$ All these factors increase the LH/FSH ratio; the most obvious neuroendocrine characteristic regulating abnormal ovarian follicle maturity in PCOS is increased LH pulsatility regarding both frequency and amplitude, with relatively low FSH secretion. ${ }^{25}$ On account of an increased LH/ FSH ratio, the ovarian granulosa cells cannot aromatize the androgens to estrogens, which leads to diminished estrogen levels and ensuing anovulation ${ }^{26}$ that are consistent with our results.

AMH levels in PCOS women emphatically correspond with antral follicle number and androgen levels, are increased 2-3 fold, ${ }^{27}$ and are lessened in parallel with a decrease of androgen level in our study.

The most excellent therapeutic approach for weight reduction in obese PCOS women has not yet been explored. Lifestyle changes, mainly a caloric restriction diet alone or with exercises, ${ }^{28}$ are suggested as a first-line of treatment in the overweight and obese PCOS women. ${ }^{29}$ Dietetic-induced weight reduction enhances IR and hyperinsulinemia. Both fasting and glucose-stimulated insulin are predisposed to significantly diminish after a weight reduction by about $5 \%-10 \%{ }^{28}$ 
Table 3. Comparison of the Mean of Outcomes Measures Within Study Group After 12 Weeks of Intervention

\begin{tabular}{lccc}
\hline \multirow{2}{*}{ Variables } & \multicolumn{2}{c}{ Mean \pm SD Outcomes Measures } & \\
\cline { 2 - 3 } & \multicolumn{2}{c}{ Study Group $(\mathbf{n}=\mathbf{1 1})$} & \\
\cline { 2 - 3 } $\mathrm{BMI}\left(\mathrm{kg} / \mathrm{m}^{2}\right)$ & $27.15 \pm 2.1$ & $25.6 \pm 0.1$ & 0.04 \\
$\mathrm{FF}, \mathrm{ng} / \mathrm{dL}$ & $2.1 \pm 0.1$ & $1.09 \pm 0.1$ & 0.02 \\
$\mathrm{TT}, \mathrm{ng} / \mathrm{dL}$ & $69.5 \pm 2.1$ & $60.0 \pm 0.1$ & 0.04 \\
$\mathrm{LH}, \mathrm{mIU} / \mathrm{mL}$ & $10.1 \pm 1.3$ & $6.9 \pm 0.9$ & 0.01 \\
$\mathrm{FSH}, \mathrm{mIU} / \mathrm{mL}$ & $4.9 \pm 0.8$ & $4.8 \pm 0.6$ & 0.52 \\
$\mathrm{LH} / \mathrm{FSH} \mathrm{ratio}$ & $2.4 \pm 0.3$ & $1.3 \pm 0.0$ & 0.02 \\
$\mathrm{AMH}, \mathrm{ng} / \mathrm{mL}$ & $12.0 \pm 1.9$ & $8.5 \pm 1.3$ & 0.01 \\
$\mathrm{HOMA}-\mathrm{IR}$ & $2.9 \pm 1.3$ & $1.9 \pm 1.5$ & 0.01 \\
\hline
\end{tabular}

Table 4. Comparison of the Mean of Outcomes Measures Within Control Group After 12 Weeks of Intervention

\begin{tabular}{lccc}
\hline \multirow{2}{*}{ Variables } & \multicolumn{2}{c}{$\begin{array}{c}\text { Mean } \pm \text { SD Outcomes Measures } \\
\text { Control Group }(\mathbf{n = 1 0})\end{array}$} & \\
\cline { 2 - 3 } & Baseline & End of Intervention & \multirow{P}{*}{$\boldsymbol{P}$ Value } \\
\hline $\mathrm{BMI}\left(\mathrm{kg} / \mathrm{m}^{2}\right)$ & $26.9 \pm 1.7$ & $25.0 \pm 1.2$ & 0.04 \\
$\mathrm{FF}, \mathrm{ng} / \mathrm{dL}$ & $1.9 \pm 0.3$ & $1.5 \pm 0.05$ & 0.01 \\
$\mathrm{TT}, \mathrm{ng} / \mathrm{dL}$ & $66.3 \pm 1.3$ & $63.0 \pm 1.9$ & 0.05 \\
$\mathrm{LH}, \mathrm{mIU} / \mathrm{mL}$ & $11.3 \pm 0.3$ & $9.9 \pm 0.2$ & 0.02 \\
$\mathrm{FSH}, \mathrm{mIU} / \mathrm{mL}$ & $5.0 \pm 0.2$ & $4.8 \pm 0.4$ & 0.45 \\
$\mathrm{LH} / \mathrm{FSH} \mathrm{ratio}$ & $2.5 \pm 0.5$ & $2.0 \pm 0.6$ & 0.03 \\
$\mathrm{AMH}, \mathrm{ng} / \mathrm{mL}$ & $13.3 \pm 1.4$ & $11.9 \pm 0.9$ & 0.04 \\
$\mathrm{HOMA}-\mathrm{IR}$ & $2.5 \pm 1.4$ & $2.1 \pm 0.7$ & 0.05 \\
\hline
\end{tabular}

Table 5. Comparison of Mean Outcomes Measures Between the 2 Groups After 12 Weeks of Intervention

\begin{tabular}{lccc}
\hline \multirow{2}{*}{ Variables } & \multicolumn{2}{c}{ Mean \pm SD Outcomes Measures } & \\
\cline { 2 - 3 } & $\begin{array}{c}\text { Study Group } \\
(\mathbf{n}=\mathbf{1 1})\end{array}$ & $\begin{array}{c}\text { Control Group } \\
(\mathbf{n}=\mathbf{1 0})\end{array}$ & P Value \\
\hline $\mathrm{BMI}\left(\mathrm{kg} / \mathrm{m}^{2}\right)$ & $25.6 \pm 0.1$ & $25.0 \pm 1.2$ & 0.51 \\
$\mathrm{FF}, \mathrm{ng} / \mathrm{dL}$ & $1.09 \pm 0.1$ & $1.5 \pm 0.05$ & 0.01 \\
$\mathrm{TT}, \mathrm{ng} / \mathrm{dL}$ & $60.0 \pm 0.1$ & $63.0 \pm 1.9$ & 0.05 \\
$\mathrm{LH}, \mathrm{mlU} / \mathrm{mL}$ & $6.9 \pm 0.9$ & $9.9 \pm 0.2$ & 0.02 \\
$\mathrm{FSH}, \mathrm{mIU} / \mathrm{mL}$ & $4.8 \pm 0.6$ & $4.8 \pm 0.4$ & 0.67 \\
$\mathrm{LH} / \mathrm{FSH} \mathrm{ratio}$ & $1.3 \pm 0.0$ & $2.0 \pm 0.6$ & 0.03 \\
$\mathrm{AMH}, \mathrm{ng} / \mathrm{mL}$ & $8.5 \pm 1.3$ & $11.9 \pm 0.9$ & 0.01 \\
$\mathrm{HOMA}-\mathrm{IR}$ & $1.9 \pm 1.5$ & $2.1 \pm 0.7$ & 0.04 \\
\hline
\end{tabular}

A significant decrease of total and free testosterone levels after dietetic-induced weight reduction was affirmed and agreed with our study. Additionally, controlled trials have obtained similar outcomes, despite the fact that others did not report any impact. Weight reduction can be followed by a significant improvement in SHBG concentration, which is steady with a diminishment of the free androgen..$^{28,30}$

In spite of the fact that exercise in overweight or obese PCOS women enhances insulin sensitivity, the impact of exercise is by all accounts through mechanisms inconsequential to weight reduction ${ }^{31}$; exercise can improve rates of glucose clearance and the skeletal muscle sensitivity take-up to insulin. ${ }^{32}$

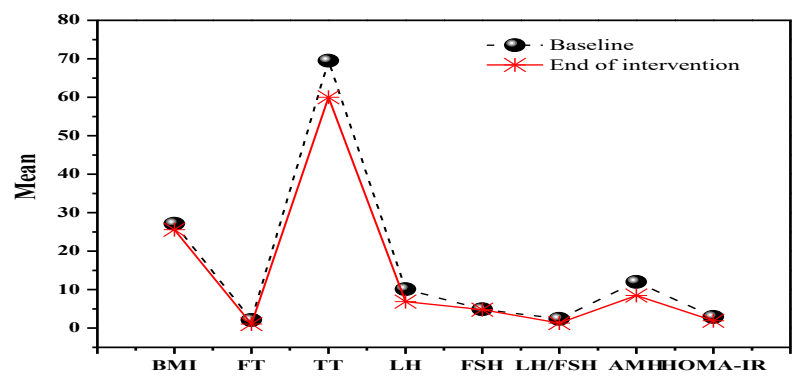

Figure 2. Outcomes Measures Within the Study Group.

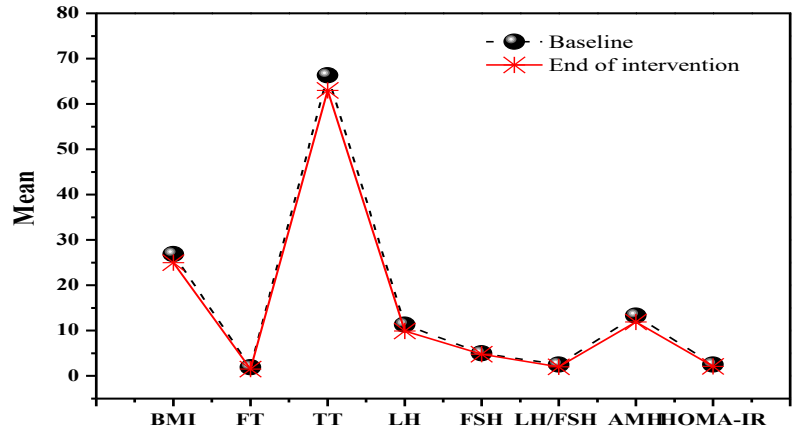

Figure 3. Outcomes Measures Within the Control Group.

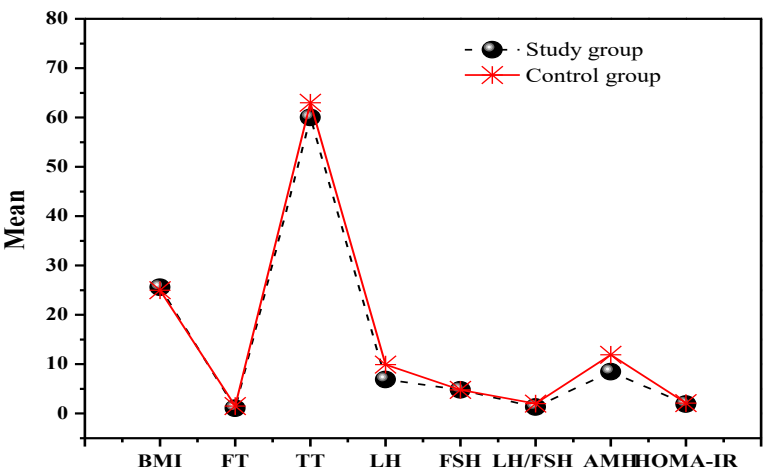

Figure 4. Comparison of Mean Outcomes Measures Between the 2 Groups at the End of Intervention.

In the present study, diminished HOMA, IR is an indication of progress in insulin sensitivity and decreased IR.

Chronic anovulation is a common characteristic of PCOS women, and the return of ordinary ovulatory function represents the main target to be accomplished for PCOS women complaining of ovarian dysfunction and/or infertility.

In our study, the menstrual pattern was as follows: 6 of 9 reported 3 regular menses in the study group, with 5 of 7 reported 3 regular menses in the control group.

The mechanisms responsible for the beneficial outcome of weight reduction on menses changes and fertility likely rely upon the parallel reduction of both hyperinsulinemia 
and hyperandrogenemia. Evidence exists that dieteticinitiated weight reduction may enhance both menstrual variations from the norm and spontaneous ovulation in the larger part of PCOS women. ${ }^{33}$ Unexpectedly, it ought to be noted that obtainable information on the results of weight reduction on menses variations from the norm among obese PCOS women have frequently been obtained in uncontrolled trials, in studies including a control group who neglected to complete the study protocol, and even with insignificant (5\% of baseline) weight reduction throughout treatment. ${ }^{34}$

Our data suggest improved outcomes for PCOS women treated with laser acupoints (SG) compared with those treated with placebo laser acupoints (CG). The mechanism, by which laser influences the insulin sensitivity, is still unknown. Notwithstanding, there are numerous physiological proposals that may clarify the change in insulin sensitivity. ${ }^{35}$ It has also been found that women with PCOS have low-grade inflammation, which might be a reason for IR.

Use of laser reduces the level of cytokines discharged from white blood cells (inflammatory response) ${ }^{36}$; cytokines such as TNF-alpha, IL-1 beta, and IL-8 proteins contribute to IR and atherosclerosis. ${ }^{37}$

Utilization of laser stimulates the respiratory electron transport chain, resulting in (1) changes in the reduction/ oxidation status of the mitochondria which leads to enhanced ATP synthesis (Krebs cycle), (2) activation of sodium/potassium pump modifies cell membrane permeability to the flow of calcium. ${ }^{38}$

The enhancement of ions transportation over the cell membrane, that occur in instances of hyperinsulinemia or IR, may enhance the insulin action on the cells and contribute to lessening the insulin level. ${ }^{39}$

These acupoints compare to particular regions on the body surface, which exhibit high electrical conductance on account of the existence of high density of gap junctions alongside cell margins. They go about as convergent points for electromagnetic fields. A high metabolic rate, high temperature, and calcium ion concentration are likewise seen at these points. ${ }^{40}$

Laser is a type of electromagnetic radiation used to stimulate acupuncture points using the same principles of point determination as for needle acupuncture.

An explanation for the changes for PCOS women in the SG compared with those in the CG is that laser acupoint placed in the identical innervation part as the ovary reduces sympathetic activity that prompts diminished discharge of ovarian androgens. In parallel, the action of higher centers is modulated by the discharge of opioids, specifically B-endorphin which thusly influence $\mathrm{GnRH}$ secretion and the menstrual cycle. Animal studies have exposed that acupuncture therapy standardized GnRH emission and influenced peripheral GnRH levels. ${ }^{41}$ In women with PCOS, there is an increased sympathetic nerve activity and an increased B-endorphin secretion.
Laser acupoint diminishes central B-endorphin, causing a decreased sympathetic tone, decreased $\mathrm{LH}$ and release of B-endorphin into the circulation system. Different investigators have exposed that, acupuncture likewise affected serum levels of LH, FSH, E2, and P in typically ovulatory or anovulatory women. ${ }^{42}$ Another study by Stener-Victorin et $\mathrm{al}^{14}$ assessed the impact of electroacupuncture (EA) for induction of ovulation on 24 PCOS women. The proportion of menstrual cycles in all participants appeared to be enhanced by $15 \%-66 \%$ up to 3 months post-treatment. The BMI, waist/hip circumference ratio, LH/FSH ratio, serum testosterone concentrations and the B-endorphin concentration diminished significantly after treatment, showing that acupuncture could be considered as an option or subordinate to pharmacological induction of ovulation. Through its central sympathetic-inhibitory impact, acupuncture may diminish uterine artery resistance and in this way, improve uterine blood flow. ${ }^{43}$ The peripheral influence of acupuncture in enhancing uterine blood flow and hereafter endometrial thickness also gives encouraging information in regards to its potential positive effect on implantation and enhancement of infertility treatment outcomes. As of late, skin light contact has appeared to stimulate mechanoreceptors with slow conducting unmyelinated $(\mathrm{C})$ afferents which regulate activity in the central nervous system ${ }^{44}$ of both groups in our study. Limitations of our study were changes in the factors: psycho-physiological, social and cultural level of PCOS participants, which may or may not have had an impact on the outcomes, but until now have not been clarified in the literature. Future scientific studies on the effectiveness of various physical therapy modalities as ultrasonic acupoints in the treatment of PCOS women is really advised.

\section{Conclusion}

Based on the present analysis, laser acupoints stand for an efficient and safe form of acupuncture for the treatment of PCOS women and could be considered as a viable alternative or complement to pharmacological induction of ovulation.

\section{Conflict of Interests}

The authors declare that they have no competing interests.

\section{Ethical Considerations}

The proposal of this study was approved by the research ethics committee, Faculty of Physical therapy, Cairo University (No: P.T. REC/012/001534) and by the Local Review Board of Kafrelsheikh General Hospital.

\section{Acknowledgement}

The authors appreciatively acknowledge every one of the participants, doctors, physiotherapists, and nurses for the exertion dedicated to this work. 


\section{References}

1. Azziz R, Woods KS, Reyna R, Key TJ, Knochenhauer ES, Yildiz BO. The prevalence and features of the polycystic ovary syndrome in an unselected population. J Clin Endocrinol Metab. 2004;89(6):2745-2749. doi:10.1210/ jc.2003-032046

2. Norman RJ, Wu R, Stankiewicz MT. 4: Polycystic ovary syndrome. Med J Aust. 2004;180(3):132-137.

3. Badawy A, Elnashar A. Treatment options for polycystic ovary syndrome. Int J Womens Health. 2011;3:25-35. doi:10.2147/ijwh.s11304

4. Stepto NK, Cassar S, Joham AE, et al. Women with polycystic ovary syndrome have intrinsic insulin resistance on euglycaemic-hyperinsulaemic clamp. Hum Reprod. 2013;28(3):777-784. doi:10.1093/humrep/des463

5. Azziz R, Carmina E, Dewailly D, et al. Positions statement: criteria for defining polycystic ovary syndrome as a predominantly hyperandrogenic syndrome: an Androgen Excess Society guideline. J Clin Endocrinol Metab. 2006;91(11):4237-4245. doi:10.1210/jc.2006-0178

6. Zawadski JK, Dunaif A. Diagnostic criteria for polycystic ovary syndrome: towards a rational approach. In: Dunaif A, Givens JR, Haseltine FP, Merriam GR, eds. Polycystic Ovary Syndrome. 1st ed. Oxford: Blackwell Scientific Publications;1992:377-384.

7. Revised 2003 consensus on diagnostic criteria and longterm health risks related to polycystic ovary syndrome (PCOS). Hum Reprod. 2004;19(1):41-47.

8. Azziz R, Carmina E, Dewailly D, et al. The Androgen Excess and PCOS Society criteria for the polycystic ovary syndrome: the complete task force report. Fertil Steril. 2009;91(2):456-488. doi:10.1016/j.fertnstert.2008.06.035

9. ACOG Practice Bulletin No. 108: Polycystic ovary syndrome. Obstet Gynecol. 2009;114(4):936-949. doi:10.1097/AOG.0b013e3181bd12cb

10. March WA, Moore VM, Willson KJ, Phillips DI, Norman RJ, Davies MJ. The prevalence of polycystic ovary syndrome in a community sample assessed under contrasting diagnostic criteria. Hum Reprod. 2010;25(2):544-551. doi:10.1093/ humrep/dep399

11. Gilling-Smith C, Story H, Rogers V, Franks S. Evidence for a primary abnormality of thecal cell steroidogenesis in the polycystic ovary syndrome. Clin Endocrinol (Oxf). 1997;47(1):93-99.

12. Heider U, Pedal I, Spanel-Borowski K. Increase in nerve fibers and loss of mast cells in polycystic and postmenopausal ovaries. Fertil Steril. 2001;75(6):11411147.

13. Lanham MS, Lebovic DI, Domino SE. Contemporary medical therapy for polycystic ovary syndrome. Int $J$ Gynaecol Obstet. 2006;95(3):236-241. doi:10.1016/j. ijgo.2006.08.004

14. Stener-Victorin E, Waldenstrom U, Tagnfors U, Lundeberg T, Lindstedt G, Janson PO. Effects of electro-acupuncture on anovulation in women with polycystic ovary syndrome. Acta Obstet Gynecol Scand. 2000;79(3):180-188.

15. Whittaker P. Laser acupuncture: past, present, and future. Lasers Med Sci. 2004;19(2):69-80. doi:10.1007/s10103-0040296-8

16. Stener-Victorin E, Jedel E, Janson PO, Sverrisdottir
YB. Low-frequency electroacupuncture and physical exercise decrease high muscle sympathetic nerve activity in polycystic ovary syndrome. Am J Physiol Regul Integr Comp Physiol. 2009;297(2):R387-395. doi:10.1152/ ajpregu.00197.2009

17. Beijing college of traditional medicine, Shanghai college of traditional medicine, Nanjing college of traditional medicine and The acupuncture institute of the academy of college of traditional medicine. Essentials of Chinese acupuncture. Beijing: Foreign languages press; 1980.

18. Douglas CC, Norris LE, Oster RA, Darnell BE, Azziz $\mathrm{R}$, Gower BA. Difference in dietary intake between women with polycystic ovary syndrome and healthy controls. Fertil Steril. 2006;86(2):411-417. doi:10.1016/j. fertnstert.2005.12.054

19. Carmina E, Legro RS, Stamets K, Lowell J, Lobo RA. Difference in body weight between American and Italian women with polycystic ovary syndrome: influence of the diet. Hum Reprod. 2003;18(11):2289-2293.

20. Matthews DR, Hosker JP, Rudenski AS, Naylor BA, Treacher DF, Turner RC. Homeostasis model assessment: insulin resistance and beta-cell function from fasting plasma glucose and insulin concentrations in man. Diabetologia. 1985;28(7):412-419. doi:10.1007/BF00280883

21. Burghen GA, Givens JR, Kitabchi AE. Correlation of hyperandrogenism with hyperinsulinism in polycystic ovarian disease. J Clin Endocrinol Metab. 1980;50(1):113116. doi:10.1210/jcem-50-1-113

22. Tosi F, Negri C, Perrone F, et al. Hyperinsulinemia amplifies GnRH agonist stimulated ovarian steroid secretion in women with polycystic ovary syndrome. J Clin Endocrinol Metab. 2012;97(5):1712-1719. doi:10.1210/jc.2011-2939

23. Taylor AE, McCourt B, Martin KA, et al. Determinants of abnormal gonadotropin secretion in clinically defined women with polycystic ovary syndrome. J Clin Endocrinol Metab. 1997;82(7):2248-2256. doi:10.1210/jcem.82.7.4105

24. Rebar R, Judd HL, Yen SS, Rakoff J, Vandenberg G, Naftolin F. Characterization of the inappropriate gonadotropin secretion in polycystic ovary syndrome. J Clin Invest. 1976;57(5):1320-1329. doi:10.1172/jci108400

25. Patel K, Coffler MS, Dahan MH, Malcom PJ, Deutsch R, Chang RJ. Relationship of GnRH-stimulated LH release to episodic LH secretion and baseline endocrine-metabolic measures in women with polycystic ovary syndrome. Clin Endocrinol (Oxf). 2004;60(1):67-74.

26. Azziz R. Diagnostic criteria for polycystic ovary syndrome: a reappraisal. Fertil Steril. 2005;83(5):1343-1346. doi:10.1016/j.fertnstert.2005.01.085

27. Piltonen T, Morin-Papunen L, Koivunen R, Perheentupa A, Ruokonen A, Tapanainen JS. Serum anti-Mullerian hormone levels remain high until late reproductive age and decrease during metformin therapy in women with polycystic ovary syndrome. Hum Reprod. 2005;20(7):18201826. doi:10.1093/humrep/deh850

28. Pasquali R, Gambineri A. Treatment of the polycystic ovary syndrome with lifestyle intervention. Current Opinion in Endocrinology, Diabetes and Obesity. 2002;9(6):459-468.

29. Hutchison SK, Teede HJ, Rachon D, Harrison CL, Strauss BJ, Stepto NK. Effect of exercise training on insulin sensitivity, mitochondria and computed tomography muscle attenuation in overweight women with and without 
polycystic ovary syndrome. Diabetologia. 2012;55(5):14241434. doi:10.1007/s00125-011-2442-8

30. Gambineri A, Pelusi C, Vicennati V, Pagotto U, Pasquali R. Obesity and the polycystic ovary syndrome. Int J Obes Relat Metab Disord. 2002;26(7):883-896. doi:10.1038/ sj.ijo.0801994

31. Harrison CL, Stepto NK, Hutchison SK, Teede HJ. The impact of intensified exercise training on insulin resistance and fitness in overweight and obese women with and without polycystic ovary syndrome. Clin Endocrinol (Oxf). 2012;76(3):351-357. doi:10.1111/j.1365-2265.2011.04160.x

32. Mikines KJ, Sonne B, Farrell PA, Tronier B, Galbo H. Effect of physical exercise on sensitivity and responsiveness to insulin in humans. Am J Physiol. 1988;254(3 Pt 1):E248259. doi:10.1152/ajpendo.1988.254.3.E248

33. Pasquali R, Gambineri A, Pagotto U. The impact of obesity on reproduction in women with polycystic ovary syndrome. BJOG. 2006;113(10):1148-1159. doi:10.1111/ j.1471-0528.2006.00990.x

34. Hollmann M, Runnebaum B, Gerhard I. Effects of weight loss on the hormonal profile in obese, infertile women. Hum Reprod. 1996;11(9):1884-1891.

35. El-Mekawy HS, ElDeeb AM, Ghareib HO. Effect of laser acupuncture combined with a diet-exercise intervention on metabolic syndrome in post-menopausal women. J Adv Res. 2015;6(5):757-763. doi:10.1016/j.jare.2014.08.002

36. Yamaura M, Yao M, Yaroslavsky I, Cohen R, Smotrich M, Kochevar IE. Low level light effects on inflammatory cytokine production by rheumatoid arthritis synoviocytes. Lasers Surg Med. 2009;41(4):282-290. doi:10.1002/ lsm.20766

37. Despres JP. Abdominal obesity: the most prevalent cause of the metabolic syndrome and related cardiometabolic risk. Eur Heart J Suppl. 2006;8(suppl_B):B4-B12. doi:10.1093/ eurheartj/sul002

38. Karu TI. Molecular mechanisms of therapeutic effects of low intensity laser radiation. Lasers Life Sci.1988;2(1):5374.

39. Sorensen SS, Christensen F, Clausen T. The relationship between the transport of glucose and cations across cell membranes in isolated tissues. X. Effect of glucose transport stimuli on the efflux of isotopically labelled calcium and 3-O-methylglucose from soleus muscles and epididymal fat pads of the rat. Biochim Biophys Acta. 1980;602(2):433445.

40. Chang R, Chung PH, Rosenwaks Z. Role of acupuncture in the treatment of female infertility. Fertil Steril. 2002;78(6):1149-1153.

41. Yang SP, Yu J, He L. Release of gonadotropin-releasing hormone $(\mathrm{GnRH})$ from the medio-basal hypothalamus induced by electroacupuncture in conscious female rabbits. Acupunct Electrother Res. 1994;19(1):19-27.

42. Aso T, Motohashi T, Murata M, Nishimura T, Kakizaki $\mathrm{K}$. The influence of acupuncture stimulation on plasma levels of LH, FSH, progesterone and estradiol in normally ovulating women. Am J Chin Med (Gard City N Y). 1976;4(4):391-401.

43. Stener-Victorin E, Waldenstrom U, Andersson SA, Wikland M. Reduction of blood flow impedance in the uterine arteries of infertile women with electro-acupuncture. Hum Reprod. 1996;11(6):1314-1317.

44. Olausson H, Lamarre Y, Backlund H, et al. Unmyelinated tactile afferents signal touch and project to insular cortex. Nat Neurosci. 2002;5(9):900-904. doi:10.1038/nn896 